\title{
Weakening of the Sense of Body Ownership in Schizophrenia: Implications for the Psychological Mechanism of Anxiety Reduction
}

\author{
Beata Mirucka ${ }^{1}$ \\ Published online: 13 April 2017 \\ (C) The Author(s) 2017. This article is published with open access at Springerlink.com
}

\begin{abstract}
The main aim of the study discussed in the present paper was to explore the role of disturbances of bodily experience (of the sense of body ownership) in the regulation of a general emotional state. An attempt was made to verify the hypothesis that the autonomic emotional response (i.e. the objective state of stress) and the subjective sense of stress in schizophrenic subjects would be markedly weakened due to the Rubber Hand Illusion, whereas it was suggested that no such change would appear in the control group consisting of healthy subjects. In the 64 subjects who participated in the study (31 schizophrenic subjects and 33 subjects with no diagnosed mental condition), general emotional state was measured before and after the induction of the Rubber Hand Illusion, with the general emotional state understood as the objective state (electrodermal response) and the subjective state (the sense of stress or relaxation). Experimentallyinduced change in the sense of body ownership appeared to be a factor regulating the subjective and the objective emotional states in all subjects, although the type of change differed significantly between the groups. In the schizophrenic group, the induction of the Rubber Hand Illusion substantially reduced the subjective and objective states of stress, whilst in the control group an intensified electrodermal response was observed (objective state of stress), with the subjective emotional state remaining unaltered.
\end{abstract}

Keywords Schizophrenia - Sense ofbody ownership · Rubber hand illusion $\cdot$ Anxiety $\cdot$ Electrodermal response

Beata Mirucka

beatamir1@wp.pl

1 Faculty of Pedagogy and Psychology, University of Białystok, Świerkowa 20, 15-328 Białystok, Poland

\section{Introduction}

Schizophrenia is a disorder of the self, manifested through deep changes of self-consciousness accompanied by disorganisation processes (Sass and Parnas 2003; Parnas 2011). Self-consciousness disorders occur at the most basic, pre-verbal level of body consciousness (De Vignemont 2011; Legrand 2007), while the latter concerns the sense of body ownership along with the sense of agency (Tsakiris and Haggard 2005). Due to those disorders, persons with schizophrenia experience their bodies as an external object rather than an integral part of the Self (Sass and Parnas 2003), and in consequence they suffer from a reduced feeling of being alive (Laing 1960). Changes in experiencing one's body, the most significant manifestation of which are depersonalization signs, are considered one of the earliest schizophrenia symptoms by some scientists (Sierra and Dawid 2011). They are the first sign of the typical symptoms of this disorder: the feeling of loss of integrity and congruity of the Self (Germine et al. 2013; Irarrazaval 2015; Lenzenweger 2010; Rohricht and Priebe 2002; Rohricht et al. 2010).

Self-consciousness is founded on body awareness, which involves the sense of body-ownership and the sense of agency (Tsakiris and Haggard 2005). Generally speaking, body ownership refers to the sense that one's body is the source of sensations (Gallagher 2000). Sensations received from different areas of the body (e.g. body surface, internal organs, vestibular system, etc.) are integrated to form a basis for specific maps of bodily states. A set of these continuously developing maps allows for the experiencing of the body as living and one's own, irrespective of whether it is in a state of action or at rest (Damasio 1994; Tsakiris and Haggard 2005).

Since 1998, one of the main experimental methods of investigating changes in the sense of body ownership has been the Rubber Hand Illusion (RHI) (Botvinick and Cohen 1998). 
In their experiment, Botvinick and Cohen demonstrated that it is possible to induce an illusion of incorporation of an external object into one's body - in this case the illusion of owning a rubber hand instead of one's own. Synchronic stimulation of an artificial hand that was seen by the subject and their own visually occluded hand, both hands simultaneously stroked with a brush, was enough for the subject to start perceiving the rubber hand as their own within a couple of minutes. An fMRI examination revealed activation of the insula and the anterior cingulate cortex; changes were also observed in interoception related to anxiety and threat, which may prove that the rubber hand was incorporated into bodily representation both structurally and affectively (Ehrsson et al. 2007). Disturbance of temperature regulation observed in the real hand may suggest that the somatosensory information processing speed in this limb slowed down (Moseley et al. 2008). The RHI procedure provided a method of manipulating and altering the processes of embodiment, as well as of the online body representations. The strength of the illusion was measured in different ways. The RHI Questionnaire served as the subjective and phenomenological measure of the experimental distortion of the sense of body ownership. The questionnaire initially consisted of nine items, rated by the participants on the seven-point scale (Botvinick and Cohen 1998), and was accompanied by an objective measure: a proprioceptive drift, or a stimulation-dependent change of real hand temperature. An attempt was also made to investigate changes in the autonomic nervous system (ANS) (i.e. skin conductance responses, SCR), but solely with a threat-stimulus presented to the rubber-hand, and not as a response to the disturbed sense of body ownership (Peled et al. 2003). To our knowledge, the only exception is the study by Braithwaite and Broglia (2014), focusing on electrodermal activity (EDA) directly related to a pre-illusion state, i.e. during the time period leading up to the actual induction of the illusion and hence to the change of bodily representation (image). The study was conducted in a group of healthy subjects and in a group with anomalous bodily experience; the results showed that during the RHI procedure there was a marked increase of SCR (or electrodermal response, EDR) in both groups; however, in the second group the autonomic emotional response was significantly stronger. It was argued that EDR increase was due to the fact that the established bodily representation (body image) competes with the incoming sensory information during the RHI procedure, which destabilizes the existing body image. Disturbances of unconscious processes of multimodal integration caused changes in autonomic emotional processing (Braithwaite and Broglia 2014).

Schizophrenics are more susceptible to RHI than individuals with no psychotic disorders, which means that in people with schizophrenia the illusion is induced far sooner (sometimes even before tactile stimulation starts), and proprioceptive drift is higher (Peled et al. 2000; Thakkar et al. 2011).
Therefore, it may be expected that in this clinical group the induction of the rubber hand illusion, which distorts bodily experience, would be accompanied by a change in EDR as an indication of an unconscious emotional response. In other words, the distortion of the sense of body ownership would trigger stress (anxiety). However, such assumptions seem to be challenged by the results of studies in patients with pathological anxiety (Lader and Wing 1966), who developed symptoms of depersonalization. Once these symptoms had surfaced, EDR changed from very intense to very weak. Similarly, in a study by Giesbrecht et al. (2008) it was revealed that a strong dissociative experience, depersonalization included, instantly weakened the EDR. The diminished effect of autonomic response occurring in depersonalization is not absolute; instead, it is adjusted to the strength of the anxiety. This means that it is only after a certain level of anxiety has been exceeded that depersonalization mechanisms are activated, with the simultaneous weakening of the EDR (Sierra et al. 2006). The moment of transition to the feeling of being detached from one's body triggers a decrease in the activity level of the autonomic system (ANS), and this clearly proves a drop in the level of stress and anxiety being experienced (Sierra and Dawid 2011).

The major aim of the present study was to answer the following research question: do the disturbances in the manner of body experiencing in persons with schizophrenia significantly influence the intensity of the experienced anxiety? More precisely, does the experimentally-induced rubber hand illusion (change in feeling of body ownership) significantly lower the level of stress in persons with schizophrenia? The following hypotheses were adopted: 1) following an RHI procedure, the subjective state of stress will be considerably weakened in persons with schizophrenia, while in people with no mental disorders (control group) such a change will not occur; 2) the experimentally-induced change in the feeling of body ownership (RHI) will strongly influence the autonomic emotional reaction, being the indicator of the objective state of stress. In persons with schizophrenia the objective state of stress will decrease significantly after inducing the rubber hand illusion. At the same time, a lack of such change can be expected in the control group, and, possibly, a stress level increase and a stronger autonomic nervous system reaction due to disorders in experiencing body ownership.

\section{Method}

\section{Participants}

Sixty four subjects divided into two groups took part in the study. The patient sample included 31 individuals with schizophrenia (14 females and 17 males), aged between 19 and 40 $(M=28.42 ; S D=5.90)$. All subjects met the ICD-10 criteria; 
29 patients $(93.5 \%)$ were diagnosed as paranoid schizophrenics, and the remaining 2 patients $(6.5 \%)$ as disorganized schizophrenics. Around $32.3 \%$ of the patients fell ill before reaching 18 years of age, as opposed to the remaining $67.7 \%$, who became ill after the age of 18 . The mean average disease duration was 7.58 years $(S D=5.06)$, and was not shorter than two years in any of the cases. The number of hospitalization events varied from none to five $(M=1.90 ; S D=1.16)-12$ patients experienced a stay on a psychiatric ward once, and two patients had never been hospitalized. Nonetheless, all the patients were receiving antipsychotic medication, and - except one patient $(3.2 \%)$ - had undergone or were in the process of undergoing psychotherapy, either individual (29\%) or in a group (67.8\%). All patients were clinically stable at the time of testing. The patients with schizophrenia were recruited from a Mental Health Outpatient Clinic, where they attended regular sessions with a psychiatrist.

The healthy controls ( 23 females and 10 males), aged from 19 to $30(M=24.67 ; S D=2.63)$ were recruited through community advertising. Potential controls were excluded if they had a history of psychotic disorders.

The groups did not differ significantly in terms of age $(\mathrm{F}=2.48, \mathrm{df}(1,62), p=.12)$. Both groups were quite homogeneous in terms of demographic data such as place of living. In the control group only three persons $(9.1 \%)$, and in the schizophrenic group six (19.4\%), came from villages, while all the others were from cities. Civil status in both groups was also comparable; most of the subjects were single: $90.9 \%$ in the control group and $93.5 \%$ in the schizophrenic group. The other individuals were married. There were differences in educational level. The majority of patients suffering from schizophrenia $(74.2 \%)$ had reached secondary or vocational education level, while only 8 people $(25.8 \%)$ had higher education degrees. On the other hand, 20 individuals $(60.6 \%)$ from the control group had a higher education degree, while the remaining 13 (39.4\%) had reached secondary education level.

The study was approved by the institutional Review Board of the University of Białystok Written informed consent was obtained from all participants prior to their participation in the study. The participants were informed that they would take part in the anonymous study that would last about $20 \mathrm{~min}$. Their task would be just to look at the fake hand lying in front of them while the experimenter will brush it and their real left hand simultaneously. They were told as well that the right hand would be connected to a galvanometer in order to measure their skin reaction during the experiment.

\section{Measures}

Two questionnaires were used in the study: 1) a demographic questionnaire which included items intended to measure some demographic and socioeconomic variables, and 2) the RHI Questionnaire by Botvinick and Cohen (1998).
The self-report RHI Questionnaire is a method used to measure the rubber hand illusion, i.e. the intensity of the incorporation of the artificial hand into the subject's own body image due to experimental induction (Botvinick and Cohen 1998). The questionnaire contains 10 items, all being positive, affirmative sentences. It is completed directly after finishing the RHI procedure, and the person filling in the questionnaire refers to each statement using a 7-degree scale from A (I strongly disagree) to $G$ (I strongly agree). The sum of points received in all items is a measure of RHI intensity. High RHI results indicate a high intensity of the induced illusion, which signifies a high level of disturbance in the feeling of body ownership. On the other hand, low RHI results suggest little susceptibility to experimental induction, i.e. insignificant post-RHI procedure body ownership disturbances, or none at all. The reliability of the RHI Questionnaire in the present study is high (Cronbach's alpha $=.71$ ).

Moreover, a galvanometer (GSR 2 Biofeedback Relaxation System) was used in the study. It is a bio-medical instrument that helps to monitor the electrical resistance of the skin. It indicates an alteration in EDR. The GSR 2 precisely monitors an alteration in stress levels by translating tiny tension-related changes in skin pores into a rising or falling tone. The instrument consists of two elements: the unit with the sensing plates, where the first two fingers can be placed, and the measurement unit, with a dial indicating the scale from -10 to 10 . Negative values (from -10 to 0 ) indicate the level of the general state of relaxation (the lower the score, the higher the level of relaxation). Positive values, on the other hand, (from 0 to 10) show the general level of stress (the higher the score, the higher the level of objective anxiety).

The correct use of GSR 2 involves 1) correct calibration capacity, i.e. the capacity to stabilize the indicator at point zero, right after placing the fingers of a subject on the sensing plates, and 2) reading the direction and value of the indicator's deviation after experiencing a stimulus. The GSR 2 is very sensitive to any alteration in EDR, and is reliable (Thought Technology Ltd., 8205 Montreal). The measurement obtained indicates the change in the level of stress in comparison to the starting point, and therefore it is an ordinal measure. It was assumed that a change in general activation of the autonomic nervous system recorded as a change of electrodermal activity (EDA) reflects the state of anxiety-related psychosomatic stress. Measurement was performed twice: before the induction of RHI and after the 10-min session of tactile stimulation; this was done by determining the maximum deflection of the pointer at a certain moment of measurement. All the measurements were obtained by a single experimenter who was duly trained in the tool's use.

In the study a simple question was also used in order to measure the subjective state of stress. The question was: "At this moment, are you relaxed or stressed?" The subjects were 
asked to choose just one option ("I am relaxed." or "I am stressed."). Similarly to objective stress, the subjective state was assessed twice, before and after the RHI procedure. The subjective relaxation was coded as 0 , while stress was coded as 1 . The subjective stress variable was treated as a dichotomous measure due to the main objective: captivating the moment of change. Moreover, an attempt was made to possibly simplify the experiment on persons with schizophrenia - it was already complex and complicated due to the experimental RHI procedure.

\section{Procedure}

The experiment was conducted individually based on the classic procedure of RHI as first introduced by Botvinick and Cohen (1998). Each subject was sat at a table on which the left rubber hand was placed. At the same time, the subject's real left hand was hidden behind a screen so that it remained visually occluded. The right hand was connected to a galvanometer (GSR 2X Biofeedback Relaxation System) in such a way that finger tips rested freely on its metal part (the sensing plates). The device was then calibrated by an experimenter, who set the value at 0 . Before the RHI procedure started the subject was asked to answer the following question: "At this moment, are you relaxed or stressed?". Then, the skin conductance response (SCR) was read and recorded. Following the preliminary assessment of subjective and objective general emotional states, the experimenter initiated synchronous tactile stimulation by brushing both the rubber and real hand. The subject was asked to constantly watch the experimental rubber hand during the trial. Stimulation was stopped after ten minutes, and the subject was re-asked to assess their general emotional state in terms of relaxation or stress, and the EDR result was read. In the last stage of the experiment the subject filled out the RHI Questionnaire, which served as a subjective measure of the illusion's strength. In order to minimize the impact of disturbing variables on the stress level, proprioceptive drift was not measured.

\section{Statistical Analysis}

For all subjects the differences between the intensity of RHI were computed and submitted to a repeated measures analysis of variance (ANOVA). Subjective state of stress and objective state of stress were adjusted to the measurement level (a dichotomous scale and an ordinal scale). The generalized linear model (GLM) with repeated measures (binomial model and polynomial model) was used to analyze the differences between the factors and the significant interaction between them.

\section{Results}

In order to determine if there were significant differences in RHI intensity between the control group (subjects without a diagnosed mental disorder) and the group of patients with schizophrenia, a univariate analysis of variance (ANOVA) was performed. As a result of those analyses, a statistically significant main effect of RHI variable was obtained ( $F(1$, $62)=121.86 ; p<.001)(\mathrm{cf}$. Table 1$)$. This means that patients suffering from schizophrenia, compared to subjects from the control group, experienced disturbances in the sense of body ownership in a much more intense manner. A detailed analysis of the results shows that the biggest significant differences between groups mainly concern four experiences: 1 ) the sense of ownership of the rubber hand (Q3), 2) the sense of an increased number of limbs (Q5), 3) the sense of transformation of one's own hand into a rubber one (Q7), and 4) the sense of one's own hand becoming similar in appearance to the rubber hand $(\mathrm{Q} 9)$.

In the next step the results were subject to a statistical analysis, with the help of the generalized linear model with repeated measures. In order to verify the first hypothesis (influence of RHI on subjective level of stress) a binomial model was used, due to the dichotomous character of the dependent variable - stress was marked as 1 , while no stress was marked as 0 . To verify the second hypothesis (influence of RHI on objective level of stress) a polynomial model was employed because the measure of the dependent variable (GSR measure) was treated as an ordinal measure. Both models are logistic models, where two independent variables were taken into account: measure (pre-test/post-test) and group (control/schizophrenic). A significant interaction between the variables was searched for.

Testing of the model effects with the use of the Wald ChiSquare Test showed significant interactions for the variables: group ( $\mathrm{W}=4.97, \mathrm{df}=1, p=.026)$, measurement $(\mathrm{W}=10.50, \mathrm{df}=1, p=.002)$ and group $\mathrm{x}$ measurement $(\mathrm{W}=5.04, \mathrm{df}=1, p=.025)$. As the significance of interactions was noted, the simple effect tests was conducted separately in each group in order to compare the significance of result change (cf. Table 2).

In the control group there are no significant differences between the subjective level of stress before and after the experimental RHI manipulation, while in the group of subjects with schizophrenia the measured differences are significant. In both groups the subjective level of stress is higher before the RHI than afterwards (see Fig. 1).

Testing the effects in the second model with the use of the Wald Chi-Square Test showed significant interactions only for the measurement $\mathrm{x}$ group variable $(\mathrm{W}=50.96, \mathrm{df}=1$, $p=.001$ ). Because of the significant interactions the simple effect tests was conducted, comparing the significance of result change in the both groups separately (cf. Table 3 ). 
Table 1 Mean and standard deviation rating for each item in the self-report questionnaire RHI for each group: control and schizophrenic

\begin{tabular}{|c|c|c|c|c|c|c|}
\hline \multirow[t]{2}{*}{ Self-Report RHI Questionnaire } & \multicolumn{2}{|c|}{$\begin{array}{l}\text { Control group } \\
N=33\end{array}$} & \multicolumn{2}{|c|}{$\begin{array}{l}\text { schizophrenic } \\
\text { group } N=31\end{array}$} & \multicolumn{2}{|c|}{$\begin{array}{l}\text { Significance } \\
\text { of differences }\end{array}$} \\
\hline & M & SD & M & SD & $\mathrm{F}(1 ; 62)$ & $\mathrm{p}$ \\
\hline Q1. It seemed as if I were feeling the touch of the paintbrush where I saw the rubber hand. & 6.73 & .45 & 6.97 & .18 & 7.63 & .01 \\
\hline Q2. It seemed as though the touch I felt was caused by the paintbrush touching the rubber hand. & 6.00 & .90 & 6.45 & 1.15 & 3.08 & .08 \\
\hline Q3. I felt as if the rubber hand was my hand. & 5.48 & 1.28 & 6.61 & .56 & 20.47 & .001 \\
\hline Q4. I felt as if my real hand were drifting towards the rubber hand. & 2.85 & 1.35 & 3.58 & 1.96 & 3.06 & .08 \\
\hline Q5. It seemed as if had more than one of the hand that was being brushed. & 1.62 & 1.01 & 4.61 & 1.76 & 68.68 & .001 \\
\hline $\begin{array}{l}\text { Q6. It seemed as if the touch I was feeling came from somewhere between my own hand } \\
\text { and the rubber hand. }\end{array}$ & 2.79 & 1.27 & 3.74 & 1.63 & 6.86 & .01 \\
\hline Q7. It felt as if my real hand was turning "rubbery". & 2.57 & 1.78 & 5.48 & 1.12 & 59.95 & .001 \\
\hline Q8. It appeared visually as if the rubber hand was drifting towards my hand. & 2.91 & 1.33 & 3.84 & 1.65 & 6.16 & .05 \\
\hline $\begin{array}{l}\text { Q9. The rubber hand began to resemble my own hand in terms of shape, skin tone, freckles, } \\
\text { or some other visual feature. }\end{array}$ & 4.51 & 1.72 & 6.58 & 0.76 & 37.82 & .001 \\
\hline
\end{tabular}

Significant differences between the objective state of stress before and after the RHI induction were noted in both groups. In the group of subjects with schizophrenia the objective level of stress decreased after the RHI procedure, while in the control group the objective level of stress clearly increased (cf. Figure 2).

In order to verify whether the change in the subjective and objective states of stress in the group of subjects with schizophrenia was induced by the rubber hand illusion, and that it did not occur due to becoming familiar with the experiment's circumstances, two hypotheses were tested. The first hypothesis: the correlations between the intensity of the rubber hand illusion (RHI result) and the difference in subjective state of stress before and after the RHI significantly differ in both groups. The second hypothesis: the correlations between the RHI result and the difference in the objective state of stress before and after RHI significantly differ in both groups. The variables of differences were created $(1-$ when the post-test was higher than the pre-test, 0 - when no change occurred, -1 - when pre-test was higher than post-test). As the variable of differences has a non-parametric character, non-parametric Spearman's rho correlations were used. The correlation between the RHI result and the difference in the objective state of stress before and after RHI was $\mathrm{r}_{\mathrm{s}}=-.054(p=.769)$ in the control group, and $\mathrm{r}_{\mathrm{s}}=-.055(p=.768)$ in the schizophrenic group. Whereas the correlation between the RHI and the subjective state of stress before and after the RHI was $r_{s}=-.068$ $(p=707)$ in the control group, and $\mathrm{r}_{\mathrm{s}}=.052(p=.782)$ in the schizophrenics. The test of significance of the difference between two correlation coefficients obtained in the two groups was significant for subjective measurement $(\mathrm{z}=-2.19$, $p=0.03)$ and insignificant for objective measurement $(\mathrm{z}=0$, $p=1$ ). The difference between post-test and pre-test of the subjective measurement lowered when RHI increased, while in the group of subjects with schizophrenia it grew. Therefore, the more efficient the manipulation in the group of subjects with schizophrenia, the bigger the stress experienced by subjects with schizophrenia, and the lower the stress experienced by healthy subjects.

\section{Discussion}

The results obtained from studies in the RHI paradigm have shown that the disturbances in the sense of body ownership were far more intense in schizophrenics than in healthy controls. The rubber hand illusion occurred in both groups, but it was the schizophrenic group in which experimental distortion of body ownership was stronger and far more extensive. Additionally, the distortion was manifested not only in tactile
Table 2 Descriptive statistics (mean and standard deviation) and the Wald Chi-Square Test for each group: control and schizophrenic

\begin{tabular}{|c|c|c|c|c|c|c|c|}
\hline \multirow[t]{2}{*}{ groups } & \multicolumn{2}{|c|}{$\begin{array}{l}\text { Subjective state of stress } \\
\text { Before }\end{array}$} & \multicolumn{2}{|c|}{$\begin{array}{l}\text { Subjective state of stress } \\
\text { After }\end{array}$} & \multicolumn{3}{|c|}{ Significance of change } \\
\hline & $\mathrm{M}$ & SD & M & SD & Wald chi-square & $\mathrm{df}$ & $\mathrm{p}$ \\
\hline Control group & .36 & .49 & .27 & .45 & .61 & 1 & .43 \\
\hline $\begin{array}{l}N=33 \\
\text { Schizophrenic group } \\
N=31\end{array}$ & .77 & .42 & .22 & .42 & 18.43 & 1 & .001 \\
\hline
\end{tabular}


Fig. 1 Diagram showing the average subjective state of stress before and after the RHI procedure in the control group and in the group of subjects with schizophrenia

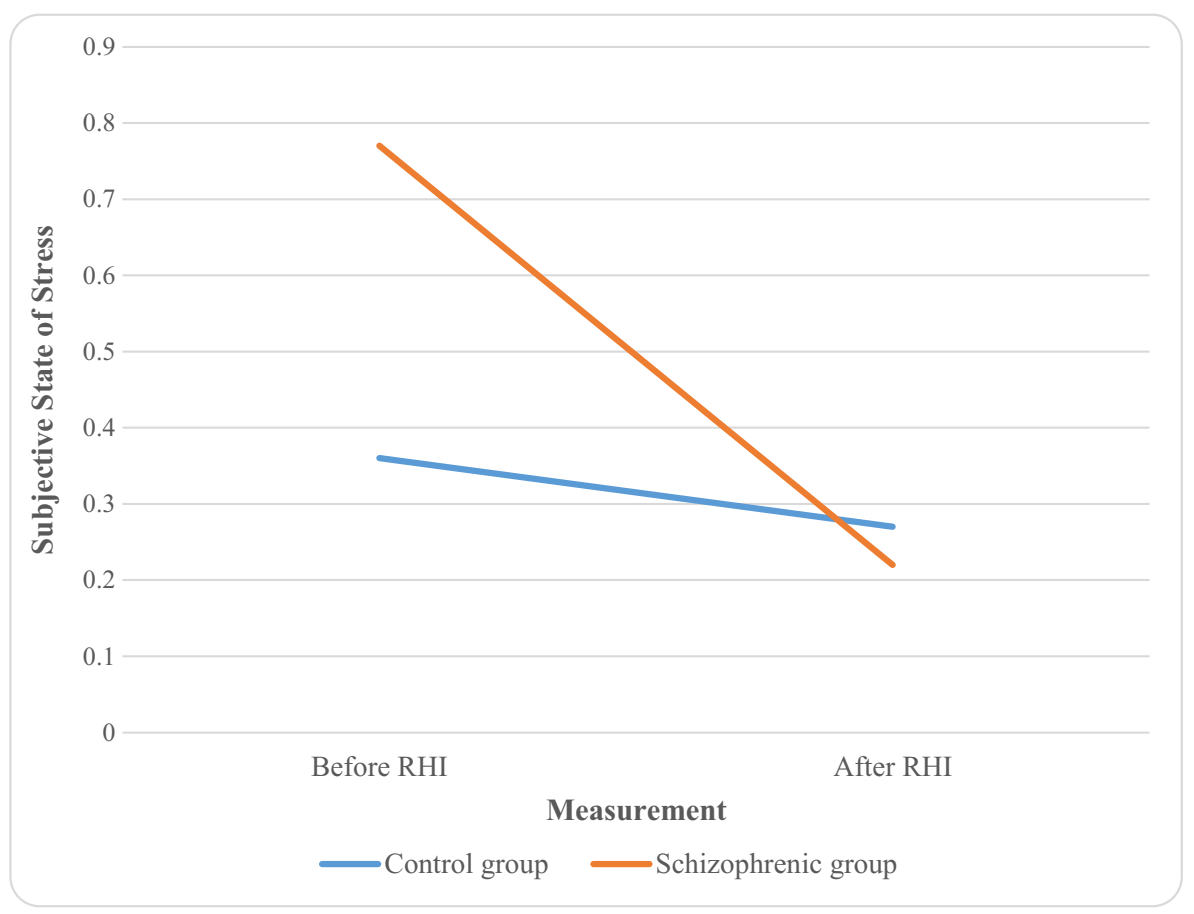

illusion (that was equally strong in both groups), but most of all in a significant change affecting bodily experience: for example, the illusory feeling of ownership of the rubber hand, of incorporation of the rubber hand into one's own body (and, consequently, the sense of increased number of limbs, or the feeling of the transformation of the rubber hand into one's own). The obtained results confirm findings from previous studies also conducted in the experimental RHI paradigm (Peled et al. 2000; Peled et al. 2003; Thakkar et al. 2011).

The experimentally induced change in the sense of body ownership appeared to be a factor regulating not only the subjective, but most of all the objective emotional state in all participants of the study. Interestingly, the type of this regulation varied significantly between the groups of subjects. In the schizophrenic group, tactile stimulation and illusory incorporation of the artificial hand substantially reduced the subjective and objective stress. In other words, due to the weakened sense of body ownership the schizophrenic patients felt less stressed and, what is more, they were aware of this change. The subjective emotional state of these patients was compatible with the objective state, which was expressed by the reported state of feeling more relaxed, and also by a marked drop in EDR strength. In the group of healthy controls, the subjects did not identify experimental disturbances of body ownership as the cause of change in their emotional state. The controls continued to report feeling relaxed, similarly to what they did before the RHI procedure was initiated. At the same time, significant changes were observed at the level of their unconscious responses of the ANS: namely, there was a marked increase in the electrodermal response strength. Although a temporary disturbance of the sense of body ownership did not affect the state of relaxation felt by these subjects, they unconsciously experienced a rise in stress
Table 3 Descriptive statistics (median and quartile deviation) and the Wald Chi-Square test for each group: control and schizophrenic

\begin{tabular}{|c|c|c|c|c|c|c|c|}
\hline \multirow[t]{2}{*}{ groups } & \multicolumn{2}{|c|}{$\begin{array}{l}\text { Objective state of stress } \\
\text { Before }\end{array}$} & \multicolumn{2}{|c|}{$\begin{array}{l}\text { Objective state of stress } \\
\text { After }\end{array}$} & \multicolumn{3}{|c|}{ Significance of change } \\
\hline & $\mathrm{ME}$ & Q & $\mathrm{ME}$ & Q & Wald chi-square & $\mathrm{df}$ & $\mathrm{p}$ \\
\hline Control group & 1.53 & 1.58 & 4.00 & 2.01 & 13.38 & 1 & .001 \\
\hline $\begin{array}{l}N=33 \\
\text { Schizophrenic group } \\
N=31\end{array}$ & 3.43 & 1.93 & .33 & 1.90 & 26.46 & 1 & .001 \\
\hline
\end{tabular}


Fig. 2 Diagram showing the average objective state of stress before and after the RHI procedure in the control group and in the group of subjects with schizophrenia

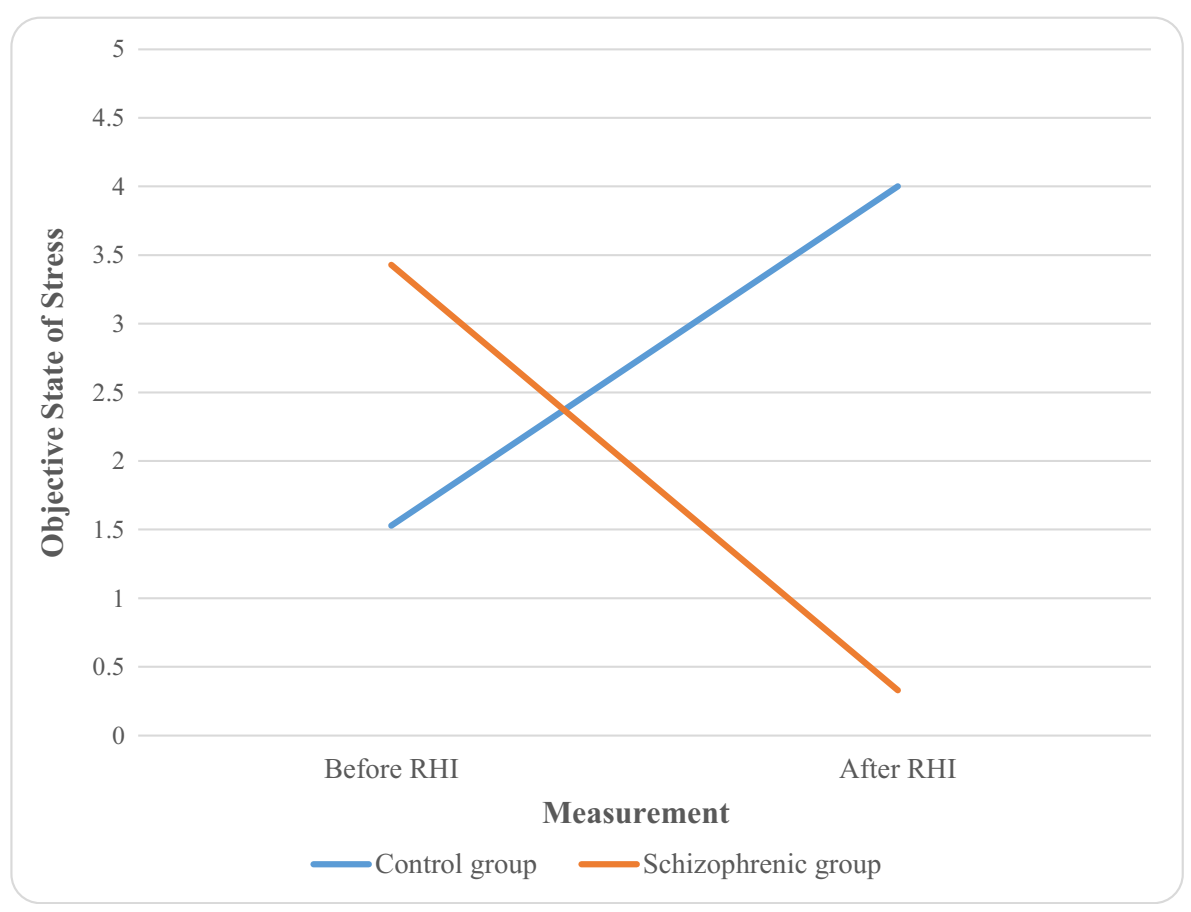

level. Differences between the study groups seem to suggest that disturbances of the awareness of the body (in this case: of the sense of body ownership) not only have some impact on emotional experiences (Damasio 1994, 1999), but they can even regulate such experiences considerably. It must be noted that the regulation varied depending on the level of selffunctioning (Bucci 2002): with a poor sense of self accompanied by disintegration processes (as in the schizophrenic group), the weakened sense of body ownership may foster alleviation of anxiety. The lower the awareness of the body, the higher the probability of reducing anxiety, which would be reflected by a general decrease of stress level and tension (Sierra and Dawid 2011). A normal (unimpaired) sense of self, presumably characterizing the controls, constituted a favourable condition for the increase in EDR and objective stress to become apparent in a situation when the sense of body ownership was challenged. The response in question may be treated as a kind of warning signal of disturbances at the level of body awareness - the fundamental, basic form of self-consciousness.

There is a puzzling inconsistency between the reported state of relaxation and the objective stress following the RHI procedure in the control group, parallel to the consistency between the subjective and objective relaxation in the schizophrenic group. The results seem to suggest that the controls, when faced with a challenge to their sense of body ownership, are less aware of their own emotional state compared to schizophrenics, who correctly interpreted a drop in stress level. Presumably, the changes of body awareness in healthy individuals, even those induced experimentally or short-term ones, inflict such disturbances of self-consciousness that are manifested by, for example, misidentification of the person's own emotional state (De Vignemont 2011; Legrand 2007). However, it still remains unclear why schizophrenics, who succumb to the rubber hand illusion far more intensively than healthy subjects, do not mistakenly identify their emotional state. Consequently, it appears that they report the state of stress rather than relaxation.

As it seems, focusing on different sources of anxiety may shed some light on this dilemma. In the control group, where the participants declared relaxation both at the beginning and at the end of the trial, the only source of anxiety was probably the experimental, relatively mild disturbance of bodily experience. The fact that the subjects did not exhibit this anxiety and clearly refused to record it may indicate that a defence mechanism of denial was activated by the (relatively) wellfunctioning self. In other words, healthy individuals attempted to cope with temporary (short-term) anxiety caused by disturbed bodily experience simply by ignoring it. In this case, the unconscious mechanism of denial might be seen as an adaptive activity of a strong self that overcomes stress at the cost of slight and temporary distortion of external reality, and thereby manages to preserve its congruity and integrity (Gabbard 2009; McWilliams 2013).

As regards schizophrenics, the main source of anxiety is most probably their distorted perception of the world and other people. Due to their insufficient degree of individuation and impaired sense of being separate, external objects are 
perceived as barely detached from the self and, consequently, pose a threat to the integrity of the subject (Carruthers 2008). Weak boundaries of the self may explain the occurrence of such positive symptoms as delusions and hallucinations (Parnas 2011). The weakening of the sense of one's own boundaries is coupled with the weakening of the sense of embodiment: the sense of being a psychosomatic unity that is mainly expressed by experiencing the body from within as the bodily self, and by experiencing everything that falls outside the boundaries of the self as external objects (Damasio 1999). Therefore, disturbing the sense of embodiment means that the body is treated and experienced as non-self rather than an integral part of the self ("embodied self"). This is probably why in persons with schizophrenia the RHI procedure contributed not so much to the induction of anxiety as a response to disturbed bodily experience as to the reinforcement of the sensation of being detached from one's body and hence to the reduction of anxiety. Just as the studies in patients suffering depersonalization symptoms revealed a flattened skin conductance response curve (i.e. lowered anxiety level) (Giesbrecht et al. 2008; Sierra and Dawid 2011), the studies in the schizophrenic group showed that weakened sense of body ownership regulated the state of stress by reducing the level of tension to the point of relaxation. Therefore, the induction of the RHI served a completely different function in each study group. In the control group it was the main trigger of anxiety, which was presumably a response to the change of body awareness (the most fundamental form of selfconsciousness) and a signal to activate defence mechanisms protecting the integrity of the self. By contrast, in the schizophrenic group a forced illusory incorporation of the rubber hand functioned only as a reinforcement of the mechanism radically weakening the sense of body ownership; this mechanism is known to be frequently employed by patients to regulate the level of social anxiety (Kepiński 1981; Salvatore et al. 2008). Due to the fact that emotions represent different states of the body, i.e. different physical states arising from the body's responses to external stimuli, the weakening of the sense of body ownership is also a way of isolating oneself from the outside world, perceived as a dangerous and hostile place.

The research study under discussion has limitations that need to be considered. One of them is the method of investigating objective and subjective stress. As for the EDR measurement, the use of a simple GSR 2X Biofeedback Relaxation System made it possible to determine the direction and size of change, but at the same time it impeded a more profound analysis of the very process of EDR (SCR) change. Taking into account the limited level of preciseness of the measurement completed using the GSR 2, the interpretation of the obtained results should be viewed with considerable caution. Using more professional equipment (e.g. Biopac System Inc.) in future research might be more appropriate for measuring subtle electrodermal activity modulations. As regards the objective state of stress, it is recommended to employ a seven-point scale instead of a two-point one to facilitate a more precise assessment of the intensity of anxiety. Future studies investigating RHI-induced physiological and emotional changes in schizophrenia should take these methodological considerations into account.

\section{Compliance with Ethical Standards}

Ethical Approval All procedures performed in studies involving human participants were in accordance with the ethical standards of the institutional and/or national research committee, and with the 1964 Helsinki declaration and its later amendments, or comparable ethical standards.

Informed Consent Informed consent was obtained from all individual participants included in the study.

Conflict of Interest The author declares that she has no conflict of interest.

Open Access This article is distributed under the terms of the Creative Commons Attribution 4.0 International License (http:// creativecommons.org/licenses/by/4.0/), which permits unrestricted use, distribution, and reproduction in any medium, provided you give appropriate credit to the original author(s) and the source, provide a link to the Creative Commons license, and indicate if changes were made.

\section{References}

Botvinick, M., \& Cohen, J. (1998). Rubber hands "feel" touch that eyes see. Nature, 391, 756.

Braithwaite, J. J., \& Broglia, E. (2014). Autonomic emotional responses to the induction of the rubber-hand illusion in those that report anomalous bodily experiences: Evidence for specific psychophysiological components associated with illusory body representations. Journal of Experimental Psychology: Human Perception and Performance, 40(3), 1131-1145.

Bucci, W. (2002). The referential process, consciousness, and the sense of self. Psychoanalytic Inquiry, 22(5), 766-793.

Carruthers, G. (2008). Types of body representation and the sense of embodiment. Consciousness and Cognition, 17, 1302-1316.

Damasio, A. R. (1994). Descartes' Error. New York: Avon Books.

Damasio, A. R. (1999). The feeling of what happens: Body and emotion in the making of consciousness. New York: Harcourt Brace.

De Vignemont, F. (2011). A self for the body. Methaphilosophy, 42(3), 230-247.

Ehrsson, H. H., Wiech, K., Weiskopf, N., Dolan, R. J., \& Passingham, R. E. (2007). Threatening a rubber hand that you feel is yours elicits a cortical anxiety response. Proceedings of the National Academy of Sciences of USA, 104(23), 9828-9833.

Gabbard, G. O. (2009). Psychodynamic Psychiatry in clinical practice. Kraków: Wydawnictwo Uniwersytetu Jagielońskiego.

Gallagher, S. (2000). Philosophical concepts of the self: Implications for cognitive sciences. Trends in Cognitive Sciences, 4, 14-21.

Germine, L., Benson, T. L., Cohen, F., \& I'Lee Hooker, C. (2013). Psychosis-proneness and the rubber hand illusion of body ownership. Psychiatry Research, 207, 45-52. 
Giesbrecht, T., Merckelbach, H., van Oorsouw, K., \& Simeon, D. (2008). Skin conductance and memory fragmentation after exposure to an emotional flip in DPD. Psychiatry Research, 177(2010), 342-349.

Irarrazaval, L. (2015). The lived body in schizophrenia: Transition from basic self-disorders to full-blown psychosis. Frontiers in Psychiatry, 6(9), 1-7.

Kępiński, A. (1981). Schizophrenia. Warszawa: PZWZ.

Lader, M. H., \& Wing, L. (1966). Physiological measures, sedative drugs and morbid anxiety. Maudsley monographs no.14. London: Oxford University Press.

Laing, R. D. (1960). The divided self. An existential study in sanity and madness. Harmondsworth: Penguin.

Legrand, D. (2007). Pre-reflective self-consciousness: On being bodily in the world. Janus Head, 9(2), 493-519.

Lenzenweger, M. F. (2010). Schizotypy and schizophrenia: The view from experimental psychopathology. New York: Guilford Press.

McWilliams, N. (2013). Psychoanalytic diagnosis. Personality structure in the clinical process. Gdańsk: Gdańskie Wydawnictwo Psychologiczne.

Moseley, G. L., Olthof, M., Venema, A., Don, S., Wijers, M., Gallace, A., \& Spence, C. (2008). Psychologically induced cooling of specific body part caused by the illusory ownership of an artificial counterpart. Proceedings of the National Academy of Sciences of USA, 105(35), 13169-13173.

Parnas, J. (2011). A disappearing heritage: The clinical core of schizophrenia. Schizophrenia Bulletin, 37(6), 1121-1130.

Peled, A., Pitsner, M., Hirchmann, S., Geva, A. B., \& Modai, I. (2000). Touch feel illusion in schizophrenia patients. Biological Psychiatry, 49(1999), 1105-1108.
Peled, A., Pressman, A., Geva, A. B., \& Modai, I. (2003). Somatosensory evoked potentials during a rubber-hand illusion in schizophrenia. Schizophrenia Bulletin, 64(2-3), 157-163.

Rohricht, F., \& Priebe, S. (2002). Do cenesthesias and body image aberrations characterize a subgroup of schizophrenia? Acta Psychiatrica Scandynavica, 105(4), 276-282.

Rohricht, F., Gudi, A., \& Lewis-Fernandez, R. (2010). Medically unexplained physical symptoms masking (Cenesthopathic) schizophrenia: A case series. Journal of Psychiatric Practice, 16(4), 258-264.

Salvatore, G., Dimaggio, G., Popolo, R., \& Lysaker, P. H. (2008). Deficits in mindreading in stressful contexts and their relationships to social withdrawal in schizophrenia. Bulletin of the Menninger Clinic, 72(3), 191-209.

Sass, L. A., \& Parnas, J. (2003). Schizophrenia, consciousness, and the self. Schizophrenia Bulletin, 29(3), 427-444.

Sierra, M., \& Dawid, A. S. (2011). Depersonalization: A selective impairment of self-awareness. Consciousness and Cognition, 20(1), 99-108.

Sierra, M., Senior, C., Phillips, M. L., \& Dawid, A. S. (2006). Autonomic response in the perception of disgust and happiness in depersonalization disorder. Psychiatry Research, 145, 225-231.

Thakkar, K. N., Nichols, H. S., McIntosh, L. G., \& Park, S. (2011). Disturbances in body ownership in schizophrenia: Evidence from the rubber hand illusion and case study of a spontaneous out-ofbody experience. PlosOne, 6(10), e27089.

Tsakiris, M., \& Haggard, P. (2005). The rubber hand illusion revisited: Visuotactile integration and self-attribution. Journal of Experimental Psychology: Human Perception and Performance, $31(1), 80-91$. 